\title{
A New Perspective on the Afterlife Issue
}

\author{
V. Krishnan \\ Kaloor, India
}

\begin{abstract}
The claim that human beings survive death as conscious entities is untenable on logical and empirical grounds. However, I suggest that a recording may persist of some aspects of one's life, of which some people may become aware under certain circumstances. I examine whether this interpretation of phenomena believed to be afterlife-related is plausible in terms of current scientific knowledge.
\end{abstract}

KEY WORDS: reincarnation; survival.

The belief that life continues after death in some form or other is ancient and widespread. But the question of whether there is any substance to that belief remains unsettled, despite years of debate and inquiry. The purpose of this paper is to point out that certain facts that have emerged from recent research can help answer that question. The belief in survival rests mainly on the assumption that there is, in each human being, a discrete entity that is the source of life and, as such, can remain intact forever, unlike the body. This discrete entity is called the soul or spirit in many cultures.

There are serious problems with this view. For example, its adherents have no verifiable answer to the question of how the soul comes into existence, a fact that is admitted by thinking theologians themselves (for example, Moore, 1966). Another unresolved puzzle is why the soul is postulated as necessary to induce life, as what develops into a child is not inert at any stage of its existence.

V. Krishnan has earned degrees in the humanities and civil engineering and writes about various scholarly subjects, most recently on new interpretations of Hindu metaphysical concepts. Reprint requests should be addressed to Mr. Krishnan at Ramakrishna Sevasram (Room No. 11), Azad Road, Kaloor, Kochi 682017, India. 
Yet another problem is the claim that the soul, unlike any other object known to us, does not ever break up into its constituents and change into other entities, a process commonly described as death, perishability, disintegration, and so on. This postulated difference between the soul and other known objects implies that there are two different orders of stuff: one perishable and one imperishable. This implication contradicts the verifiable fact that the universe, in the sense of all that is, is monistic. As I have pointed out previously in this Journal (Krishnan, 1996), the reason why there cannot be more than one order of stuff is this: No object can be destroyed totally, no matter what processes we subject it to; it will only undergo change in various respects, such as shape, size, color, molecular structure, and so on. One of the several implications of this fact is that there has never been a time without something (one or more objects) in existence, and everything that existed at any time in the past or exists now must have arisen from pre-existing things. This means that all the entities there are, animate or inanimate, are all interrelated and have something in common. That is, there is only one order of stuff and that differences that we perceive between objects are to be understood as differences in respect of properties.

It is apparent from the foregoing discussion that there are no verifiable answers to questions concerning the genesis, purpose, and composition of the postulated soul. We may therefore conclude that there is no such entity and, consequently, no life after death. What are we then to make of the claim that there are many phenomena suggestive of an afterlife? Are they all some kind of mental fabrication, such as hallucination, or plain lies? The fact is that some cases fall into these categories and some do not, as we can see from any standard work on survival research (for example, Jacobson, 1974). We can get hints about how to interpret the latter kind-those that are not fabrications - from the systematic and painstaking studies conducted by Ian Stevenson and his associates of reports of small children in various countries remembering that they had lived as another person before their birth. In some countries, particularly Eastern, such children are regarded as reincarnations of persons whose lives they recall. Stevenson, however, cautiously terms these instances cases of the reincarnation type, leaving those studying his findings to decide for themselves whether or not reincarnation is the best explanation for them (Stevenson, 1987). (I have cited only one of Stevenson's many works, as it contains a comprehensive account of his major findings about the reincarnation issue.) 
A brief explanation of the concept of reincarnation will be useful to those who are not familiar with it. Reincarnation refers to the belief that there is in every human being an entity that separates from the body at death, carrying his or her memories, skills, aptitudes, and so on, which distinguishes one person from another and can therefore be said to constitute his or her personality and, after a variable interval, unites with a child, before or after its birth. In a typical case investigated by Stevenson, the child begins to refer, usually between the ages of 2 and 5 years, by word or gesture, to persons, places, and events connected with its previous life. Full recollection is rare. The behavior of the child (the subject of a case of the reincarnation type) nearly always conforms to that of the person whose life he or she remembers (the previous personality). In some cases the subject is found to have a congenital deformity or a birthmark that corresponds in appearance and location to a wound from which its previous personality died. A few subjects are found to suffer from an internal disease, such as tuberculosis, that the pervious personality suffered from, but from which members of their new family have been free. Finally, and most importantly, the child exhibits a feeling of identity with the previous personality and an emotionally-laden connection with that person's family. This feeling of identity with the previous personality is a feature common to all the cases that have been verified satisfactorily. The other features are not equally prominent in all cases. Before proceeding further, I would like to make it clear that the conclusions I have drawn from Stevenson's studies and others are entirely my own and I alone am responsible for any shortcomings in them.

One of Stevenson's findings is that the subjects of cases of the reincarnation type are not born just anywhere. In a number of cases it was noticed that they were born near the previous personalities' place of death (Stevenson, 1987). Instances of the subject's birth far from this area are not, however, uncommon. A significant fact about many of these cases involving geographical distance is that they occurred under one or the other of the following circumstances: One of the parents of the subject, who lived far from the place where the previous personality had died, passed through it just before or soon after the conception of the subject; or the body of the previous personality had been moved from where he or she was believed to have died to another place (Stevenson, 1987). It is clear from these findings that when a person dies, a factor carrying some elements of his or her personality persists in the death-related area and becomes associated with a child 
at some stage of its development in such a way that these elements become part of its memories.

Another finding that should be noted in this connection is that a few subjects spoke of events that they felt to have taken place between their birth and the death of their previous personalities. I shall cite two examples. One child said that she was in a realm where the clothes were rich and elegant, and they needed no washing. There was no need to eat; however, food appeared before you whenever you wished for it. The girl met a kindly "ruler" who suggested to her to get reborn, but did not tell her where (Stevenson, 1987). Another child, a boy aged about 3 years, recalled a car accident in which the previous personality was involved. The impact of the crash threw the pervious personality from the car and he died "almost instantly" from a broken neck. The ambulance taking his body went over a bridge near the accident site (Stevenson, 1987).

The resemblance of these accounts to near-death experiences (NDEs) is unmistakable (although Stevenson did not describe them as NDEs). The first example is reminiscent of otherworldly NDEs and the second of an out-of-body experience (OBE). Now these children could not have known about their previous personalities' NDEs from any living person or through any other normal means, because their previous personalities died and did not live to speak of them. Some commentators on reincarnation have invoked extrasensory perception (ESP) to account for these and other kinds of rebirth memories (for example, Chari, 1962); but ESP, even if it does occur, does not help explain the kind of experience cited here because the children had not been born at the time the NDEs occurred. It seems to me that the simplest and best explanation is that an entity separated from the body at death bearing what constitutes personality, in the sense mentioned above, and remained attached to some object in the deathrelated location until it became associated with a human host.

I think that these two findings provide the strongest evidence yet in support of the belief in a surviving factor. The next question to consider is whether the surviving element is a living entity. If it is, we can be certain that there is an afterlife. Unfortunately, it is not possible to answer the question conclusively because there is no precise definition of what life is, or what the signs of life are. For example, a biochemist might say that only an object that is able to feed, reproduce, and mutate can be considered to be alive (for example, Oparin, 1957); while a philosopher might insist that consciousness is the chief sign of life (Ducasse, 1961). There is even a view that 
no clear dividing line exists between life and nonlife (for example, Beck, 1961).

Another problem is that we cannot be sure whether our notions about signs of life, which are based on embodied beings, apply to a surviving entity that is without a body like ours. We can therefore decide whether an entity is animate or not only in terms of what we know about ourselves. If a person is able to sense what is happening around him or her in a measurable way, he or she is said to be alive. I can judge the surviving factor only on this basis.

As noted above, there is a variable interval between death and rebirth. Stevenson found that this period was a "complete blank" in the memories of most of his subjects (1987, p. 109). That is, they had no recollection of matters such as where they remained in the discarnate state during the interval, any physical changes that may have occurred in the vicinity where their death occurred, what the surviving factor looked like, how it left the dead person's body and united with another person, and so on-matters that one would expect a sentient entity to register and recall fully or partially. I would therefore suggest that, on present evidence, what survives is not a living, conscious being. Some subjects have expressed their dissatisfaction with their birth in families inferior in social and/or economic status compared to their status in a previous life; further, instances of rebirth of members of hostile tribes in enemy territory have been reported (Stevenson, 1987). Such cases also seem to suggest that the surviving entity is not a conscious being capable of choosing its future parents.

If the surviving factor is not a living entity and yet carries some of the thoughts and such subjective activity of a deceased person, what is it? The answer is obvious to me: it can only be a recording of mental activity. There are also findings that suggest what is likely to be recorded. For example, most children recalled only events "of the last year, month, and days of the life remembered" (Stevenson, 1987, p. 107). Stevenson further noted: "Recency of association with the person or object (on the part of the previous personality before death) appears more important than length of association in influencing the subject's memories" (1987, p. 108). Further, there is some indication that the subject may remember only very little of the previous personality's life if the latter was suffering from poor memory at the time of his or her death (Stevenson, 1987). It is worth noting here that, apart from OBEs and otherworldly NDEs, some subjects have reported experiencing what in the NDE literature is called a life review or 
panoramic memory - a sudden, quick, and brief imaged recollection of events of life-just before dying in the previous life (Stevenson, 1987). I think it is reasonable to infer from these findings that the subject remembers only what actually went through the previous personality's mind at the time of his or her death. In short, what survives is a recording of what a dying person happens to think of. Since this provides some information about him or her, we might also describe the surviving factor as a record of information about a deceased person.

I shall now consider whether there are experimentally proven facts that support my interpretation of the surviving element. Such findings should confirm that (1) some factor having information capacity leaves the body at death, (2) that factor can persist in the physical environment for some time carrying the information it holds, and (3) a person can interact with it in such a way that he or she becomes aware, consciously or subliminally, of the information it carries.

There is evidence that all living organisms emit low-intensity light (bioluminescence) and at the time of death this electromagnetic radiation is ten to 10,000 times stronger (necrotic radiation). It is already known that this electromagnetic radiation holds simple kinds of information such as the rate of dying. Recent research, however, suggests that it may have a much larger information capacity (Slawinski, 1987a, 1987b). In other words, when a person dies, an electromagnetic radiation may occur that can carry some information about him or her. It is yet to be confirmed whether this radiation holds the kind of information that subjects of cases of the reincarnation type recall; but it is conceivable that it may, on the basis of recent studies of the mind/body relationship, which indicate that our thoughts, emotions, and mental phenomena are accompanied by characteristic brainwave patterns (Hutchinson, 1991; Ornstein, 1972). That is, a thought, for instance, is the manner in which we experience, or is the experiential aspect of, a certain brainwave pattern, just as a color is the way we experience electromagnetic radiation of a certain wavelength (Krishnan, 1994). It is then possible that the necrotic radiation may be modulated by the brainwave patterns of a dying person.

As for the other points, there are positive hints from studies concerning allergic reactions. For example, it has been found that water has a "memory" for frequencies of electromagnetic fields to which it has been exposed, and some people may react to the memory of those frequencies if they come to the neighborhood of the container in which such treated water is kept (Smith and Best, 1989). This renders theoretically sound my proposal that (1) the surviving factor is a record 
of information, such as an energetic radiation; (2) it may remain apart from the body of a dead person, attached to an animate or inanimate entity; and (3) a living person may become aware of it under certain circumstances. Other writers have already suggested that sighting of ghosts could be explained along these lines (Lethbridge, 1961; Smith and Best, 1989).

In light of the above discussion, we may conclude that surviving records of information about a dead person may explain not only cases of the reincarnation type but also other phenomena that are said to be afterlife-related and found not to be mental fabrications or fraudulent. However, it should not be assumed that the mechanism underlying them-the manner in which the record of information comes about-is identical for all afterlife-related phenomena, as there are considerable differences among them. For example, the apparition of a dead person is said to be visible, apparently projected out into space, whereas a rebirth subject appears to experience events as imaged memories, that is, as visual images in the mind (Stevenson, 1987). Subjects in a reincarnation-type case feel a sense of identity with the previous personality, while subjects of apparitional experiences do not feel the same way about the dead person.

Such differences suggest that different mechanisms are at work. This is one of the matters to be studied in the future. Some of the others are added below, from which it can be seen that a multidisciplinary effort may be necessary to find adequate answers. There are no verifiable reports of multiple rebirths, that is, more than one child recalling events from the life of the same deceased person. Even in the case of identical (one-egg) twins, either both children recalled different previous lives, or only one of them remembered a previous life. This characteristic indicates that the surviving element in cases of the reincarnation type does not split up between more than one child or inanimate environmental host. In other words, it joins its host in its entirety. There is another finding worth noting in this connection: I mentioned above that the surviving entity may remain localized in a particular area. That finding suggests that if the surviving factor is a form of energy, it does not propagate in all directions like the carrier waves from a radio broadcasting station, but rather than it radiates unidirectionally like a single photon or a highly coherent laser beam. What are the implications of these features?

Why is it that the surviving element influences the memory only of a child but not of its parents or other adults? What is the factor in an animate or inanimate entity that attracts the surviving element? How 
does the surviving element remain associated with an inanimate or nonhuman host for long periods?

Because there is no verified instance of a rebirth subject bearing physical resemblance to the previous personality who is not a relative, the surviving entity seems to have no role in shaping the appearance of the subject. However, it does seem to have some influence on the body in other, presently unknown, ways. For example, some subjects are found to have a birthmark or physical deformity corresponding to the location of a wound from which the previous personality died; the scar from a long-healed wound or a birthmark may be carried from one life to another; and some subjects are noticed to have been prone to certain internal diseases like tuberculosis when the previous personality had suffered from them (Stevenson, 1987). What is the explanation for this influence?

I hope I have been able to show that a new approach to the afterlife issue is both necessary and possible. My interpretation of afterliferelated phenomena is based on the verifiable fact that the universe is monistic and the corollary that all phenomena should therefore be explicable in terms of interaction of entities belonging to a single order of reality, or stuff. I have also pointed out some of the gaps in my interpretation that need to be filled in. That effort could contribute to other fields of inquiry, just as Stevenson's rebirth studies have contributed to our understanding of certain unsolved problems in psychology, biology, and medicine (Stevenson, 1987). Finally, I believe that the realization that we live only once, that there is nothing to look forward to beyond death, will prompt us to live in harmony with one another and our environment, and make the best of our life here on this beautiful planet Earth.

\section{References}

Beck, W. S. (1961). Modern science and the nature of life. Harmondsworth, England: Penguin Books.

Chari, C. T. K. (1962). Paranormal cognition, survival, and reincarnation. Journal of the American Society for Psychical Research, 56, 158-183.

Ducasse, C. J. (1961). The belief in a life after death. Springfield, IL: Charles C Thomas. Hutchinson, M. (1991). Megabrain (rev. ed.). New York, NY: Ballantine.

Jacobson, N. O. (1974). Life without death? New York, NY: Dell.

Krishnan, V. (1994). On the mind/body problem [Letter]. Journal of Near-Death Studies, 13, 137-138.

Krishnan, V. (1996). Misidentified flying objects [Letter]. Journal of Near-Death Studies, 14, 287-290. 
Lethbridge, T. C. (1961). Ghost and ghoul. London, England: Routledge and Kegan Paul. Moore, E. G. (1966). Survival: A reconsideration. London, England: Society for Psychical Research.

Oparin, A. I. (1957). The origin of life on the earth. Edinburgh, Scotland: Oliver and Boyd.

Ornstein, J. H. (1972). The mind and the brain. The Hague, The Netherlands: Martinus Nijhoff.

Slawinski, J. (1987a). Electromagnetic radiation and the afterlife. Journal of NearDeath Studies, 6, 79-94.

Slawinski, J. (1987b). Response to commentaries on "Electromagnetic radiation and the afterlife." Journal of Near-Death Studies, 6, 127-133.

Smith, C. W., and Best, S. (1989). Electromagnetic man. London, England: J. M. Dent.

Stevenson, I. (1987). Children who remember previous lives. Charlottesville, VA: University Press of Virginia. 